\title{
Education and Work-Experience - Influence on the Performance
}

\author{
Bhargava R. Kotur ${ }^{1}$, S. Anbazhagan ${ }^{2}$ \\ Department of Lifelong Learning, Bharathidasan University, Khajamalai Campus, Trichy, TN, India.
}

\begin{abstract}
This study investigated the different performance levels of the workers in the Chittoor Sugar factory located at the Chittoor town of South India. It was also studied how the factors education and work experience influence the performance levels of the workers in the firm. Upon study it has been understood that the two variables under investigation have direct effect on the performance of the workers to varying degrees. Workers in the medium range on educational qualification perform better compared those in the extremes and the same holds good in the case of work experience as well.
\end{abstract}

Keywords: Education, Work-Experience, Influence, Performance, Workers

\section{Introduction}

According to the common perception the educated people can do certain tasks easily and efficiently compared to the uneducated or those who are educated lesser. This is in accordance with the dictum 'knowledge is power'. It implies that a person who is knowledgeable can perform better at tasks that require that knowledge. Let aside the tasks that require the specialized knowledge but even the common tasks educated people can handle better. In fact lack of education and knowledge make a person crippled and inefficient. Here, education does not imply the formal college diplomas but, the mere knowledge of it. Though a person might not have diplomas but, the possession of knowledge will make him efficient (Van Vugt, 2006).

The same hold good in the case of a skilled or experienced worker. A worker having good experience in his job can become a leader due to his special gift of experience he acquired during the course of his work. This gives him an expert power (Andrew, 2009) and hence dependable and he is more efficient too due to the tacit (Polanyi, 1966) knowledge he has. This is in accordance to the common adage 'practice makes a man perfect'.

The aim of this research is to investigate the influence of education and work experience on the performance of the workers in the Chittoor Sugar factory located at the Chittoor town of South India.

\section{Related Literature}

It has been established that the Intellectual capital (knowledge) is a critical force that is responsible for the economical growth (Huang and Liu, 2005). In this arena of globalization, the modern business is mainly driven by the intellectual capital and the human capital helps organizations to establish and maintain their competitive advantage (MacDougall and Hurst, 2005). The educated and wise people in the organizations are responsible for creating wealth for their organizations and the mere machinery will not do this fete (GarcyaMeca and Martinez, 2005).

It has long been recognized that the human capital is an important part of the wealth of organizations and nations (Cabrita and Bontis, 2008). It has been proved that there is significant relationship between human capital, efficiency and financial performance (Maditinos et al., 2011). Knowledge measured as the Human capital has significant effect on economic performance (Rafiei et al., 2011). Human capital or the work force is the most intellectual asset in an organization (Hajiha and Hasanloo, 2011). In fact the human capital plays the main role in organizational performance (Ahmadi et al., 2011).

It has been proved that the human capital to be the most important component of intellectual capital in influencing organizational performance of pharmaceutical companies (Khalique et al., 2011). Ahangar (2011) states that the human capital is more efficient than other two types of capital (structural and physical) in terms of value creation and efficiency. Human capital is the most valuable component of intellectual capital and the companies with greater human capital efficiency tend to have better financial performance (Rahman, 2012). Some human capital indicators showed a positive and statistically significant relationship with firm performance (Seleim et al., 2007). The greatest objectives of human capital are to educate employees and maximize the intangible capabilities of knowledge, skills, and experience to create company value and increase performance (as par the study of Hsiung and Wang (2012). There is a positive relationship between human capital and knowledge creation (Ning et al., 2011). Human capital has an effect on organizational innovation according to Al-Dujaili (2012). Ghorbani et al., (2012) state that there is a significant relationship between human capital management and organizational innovation. There is direct relationship between human capital and productivity 
(Taleghani et al., 2011). Ahmadi et al., claim (2012) that there is a significant relationship between human capital and new product development performance.

Amiri et al., (2011) point out that learning at an individual level enhances human capital, that group learning increases social capital, and that organizational learning enhances structural capital. The human capital has been defined as the combined knowledge, skill, innovativeness, and ability of the organization's employees to meet the task at hand Bontis (2000). Roos et al., (2001) stated that human capital comprises of competence, skills, and intellectual agility of the individual employees. According to Stewart (2003) the human capital as "the capabilities of individuals required to provide solutions to customers" and according to Stewart the human capital is the cream of the intellectual capital. Gruian has the view (2011) that the human capital refers to the knowledge, skills and abilities of employees, i.e. professionalism, efficiency and effectiveness in improving business productivity. Allameh et al. (2010) points out that the human capital refers to the abilities, competences, and know-how of human resources. Ngah and Ibrahim (2009) point is that human capital can be divided into three dimensions: capability and potential, motivation and commitment and innovation and learning.

Ngah and Ibrahim (2011) state that human capital of one organization to another organization is totally different and that makes it difficult to imitate, difficult to copy, rare and non-replaceable. In the words of Handzic and Ozturk (2010) "the human capital is the major strength of institutions or organizations to prosper". Zambon claim that (2002) human capital is not owned by the organization, it is only rented for the period the employees spend in the organization. Human capital goes with individual when he or she leaves the organization or institution according to Sharabati et al. (2010).

Van Vugt (2006) states that: 'In ancestral environments, some situations required the possession of unique and specialized knowledge, for example, where to find a waterhole that has not yet dried up. Knowledge about where to go would have been more likely to be held by older or experienced individuals" and thus experience will make a person perform better and hence dependable. In the present time, evidence for this link between knowledge, experience and performance can still be found in professions that require a considerable amount of specialized knowledge and experience, such as in science, politics, and arts (Van Vugt, 2006). The study (Mujtaba and Kaifi, 2008), shows that Afghan leaders have higher scores on the relationship orientation which relates to better performance. This indicates that the leaders with some specialized knowledge or skill in psychology can perform better as leaders. On his study on the school principals, Nusbuga (2009) claims that education and experience brings about a change in the leadership attitudes and hence performance. Cagle (1988) has regarded experience and education as factor that determine the leadership style and performance. Katozai (2005) argued that knowledge is a chief weapon that makes a person effective as a leader and therefore a leader should be educated, experienced and qualified. Nsubuga (2009) concluded that unless principals are well equipped with knowledge and skills in management and leadership, they would not be effective.

Apart from the professional and academic knowledge, it is commonly believed that experience might play important roles on the performance of individuals. In many cultures, the myth is that as people get wiser due to more exposure and experience. For example in African culture, experience is considered as a priority for leadership positions in different organizations (Ahiazu, 1989). Trompenaars (1993) viewed that leadership styles and performance of individual differ from culture to culture and country to country depending upon life patterns, beliefs and value system or otherwise on the knowledge and experience of the people.

Finally from the work of Belal A. Kaifi, Bahaudin G. Mujtaba (2010) on their study on Afghans and Americans, they had concluded that - education and experience - indeed have their impact on the performance of individuals. Hence, it was considered very important to investigate the influence of experience and educational qualification on the leadership styles of the workers and therefore the investigation was carried out.

\section{Problem and Objectives}

There has been no known research regarding the correlation between the variables - work experience and education - on the employee performance in the Chittoor sugar factory located at the Chittoor town of south India. This study therefore aims to investigate and explore that relationship. Conforming to the above investigation the research problem is defined as follows.

To study the influence of education and work experience on the worker's performance in the Chittoor Sugar factory, located at the Chittoor town of Andhra Pradesh, South India.

The objectives could be narrowed down to the following ones on the sample of the study: 1) To investigate on work experience and education of the workers 2) To study the different performance levels of workers 3) To study the influence of work experience and educational qualification on the performance of workers. 


\section{Research Methodology}

Keeping in view of the present study, based on the research problems (given later), the research design (Kothari, 2001) is developed that could facilitates further research. This is mainly a survey research. The proposed research involves empirical testing of research problems set forth for the study and this research is involves only the qualitative study.

\section{1 Research Universe and Sample}

This research is focused on the Sugar factory at Chittoor town in the state of Andhra Pradesh, south India. The mother tongue of the local people is Telugu, a South Indian language. The firm employs around 653 employees of whom around 36 employees hold a supervisory role.

For the purposes of this research study simple random sampling has been used and the researcher was free to choose his sample from the universe of the firm. In the simple random sampling technique, every unit in the universe has the equal chance of being chosen for the study. The researcher posed no defining criteria in selecting the elements from the sample. Simple random sampling is the very primitive sampling techniques and is easiest to understand and implements as well. It dictates no criteria either on the researcher or on the member in the group.

The sample size of the research comprised 112 of the 653 workers and 16 of the 32 supervisors. The sample of 112 workers at the firm, were randomly selected (chosen) by the researcher at the firm. The researcher placed no requirements on the workers while taking the samples.

\section{2 Data Collection}

For the purposes of this research, the questionnaire was used to gather the necessary information. In an attempt to make it beneficial for both the researcher and the firm, and so as not to disrupt operations at the firm, the researcher visited the firms frequently and collected the data from the respondents (the managers or supervisors of the employees) by giving the questionnaires during the firm's lunch break time.

The performance questionnaire was given to the supervisors or managers of the employees to rate the worker's performance by scoring each individual question on the questionnaire on a scale from 1 to 5 . While the respondents answer the questionnaire, if they find any difficulty or ambiguity the researcher attended them to solve their problem and got the needed data. Each rater was allowed a period of half an hour for the completion and return of the questionnaires.

Another important point is that, majority of the workers are not good at English language. So, the questionnaire involved in this study was translated in to the mother tongue of the workers, the Telugu language so that to make their task easier. In this way the need data was collected from the firms by the researcher personally present with the respondents and this data collection took a period of over a month.

\section{3 Data Collection Instrument}

The employee performance was captured and recorded using the Performance Questionnaire of the University of the Fraser Valley employee services performance appraisal questionnaire.

The rating describes the employee's performance on each item and the evaluation scale has five (5) possible ratings, as follows. Each performance appraisal factor is measured using the scale of; 1-5. The relative meaning of the numbers from 5 to 1 is given as: Excellent - performance is consistently above acceptable performance levels, Good - performance is occasionally above acceptable performance levels and otherwise meets acceptable performance levels, Satisfactory - performance consistently meets acceptable performance levels, Sometimes-unsatisfactory - performance is occasionally below acceptable performance levels but otherwise meets acceptable performance levels and Unsatisfactory - performance is consistently below acceptable performance levels.

The supervisor or manger of the respective employee should respond to this performance questionnaire, judging the performance of his/her subordinate. Following this a total score is calculated for each employee (worker). Then that score is calculated on the scale of five again and this final score will indicate the performance of the employee, as given in the above description. Each of the 112 workers performance appraisal scores, gathered from the performance appraisal questionnaire was analyzed using the SPSS.

\subsection{Reliability and Validity of the Instrument}

This performance appraisal instrument is a component of the University of the Fraser Valley's performance management system. The performance management system embraces the firms stated values and seeks to ensure fairness, objectivity and consistency, while allowing sufficient flexibility to create the appropriate climate for positive interaction, communication and feedback regarding performance. Management of employees' performance is embedded in effective management processes and based on the following five 
processes: planning for performance, compacting, managing performance, measuring performance, and developing and encouraging performance.

The performance appraisal instrument consists of a number of performance areas, with key performance indicators such as: job outputs, people management (including supervision and leadership); interpersonal relationships, communication skills, intra-personal relations and punctuality beyond other factors according to the website of the employee services department of the University of the Fraser Valley.

This performance management system was designed more than ten years ago and has been continuously used through years and each employee under goes one performance appraisal a year in the respective departments of the university. The latest revision to the instrument was done in the year 2011 August.

All performance management matters are documented in the employee services department of the university and this instrument has been proven to exhibit good results on the performance of the employees at the university since its inception, according to the university website.

\section{5 Data Capturing}

Once all the questionnaires were collected by the researcher, the researcher coded the gathered data as needed for the study. These scores were then captured by the researcher into a Microsoft Excel spreadsheet for SPSS analysis. These scores were then imported into SPSS for analysis. The data analysis will be discussed in the later sections.

\section{6 SPSS Analysis}

The data was presented in a manner that allowed for easy analysis and testing using the Statistical Product and Service Solutions (SPSS). Once the data was imported into a SPSS spreadsheet, from the Microsoft Excel spread sheet, the researcher proceeded to calculate the necessary leadership scores as per the respective scoring keys provided along with the questionnaires, by the respective organizations. The cross tabulations were derived from the SPSS tool, for the different cases as needed in the study. Once this is done statistical tests were done depending on the need.

\section{Ethical Considerations}

All the ethical rules of the research participants, has been met in this research study. Bless and Higson Smith (2000) state that the main rules are: a) voluntary participation b) the right to privacy c) Freedom and d) Anonymity e) Confidentiality.

Even if the employees are willing, the organization might not permit for data collection. The organization concerned, though willing to permit the researcher, it might not permit in practice, fearing that the researcher might waste the valuable time of their employees, during the working hours of the organization. After all, it is not the obligation of organizations to allow the researchers to experiment on their employees! But, luckily in the present study, the concerned firm was very favorable to the researcher allowing him to collect the data from the worker. The managers of the firm permitted to collect the data strictly for the research purposes only upon the condition that the names of the workers should not be revealed though the data might be published anonymously and this was all in accordance with the organizational policies and rules.

Another ethical point in research is that of confidentiality. This is concerned with using the collected data for the promised use only and not for some other purposes. Unlike in the case of anonymity, in confidentiality the researcher could identify the respondent based on her response, but should not reveal the data in public. The respondents must be assured that the data collected from them must be used for the intended purpose only and not for something else, that could damage them in some or the other way.

The data collected for this research didn't involve any confidential information to great degree, so luckily the researcher managed to collect the data from the workers of the firm with no difficulty. In order not to take away the valuable time of the workers, and not to disrupt the work of the firm, as advised by the managers of the firm, the researcher visited the workers during the time of lunch breaks and collected the data with no or minimal possible interruption. The researcher believes that, during this research work no one was affected against the ethics of research and privacy.

\section{Response Rates}

Table 1 - Population, Sample and Response Rates

$$
\begin{array}{|l|l|l|}
\hline & \text { Workers } & \text { Supervisors } \\
\hline
\end{array}
$$




\begin{tabular}{|l|c|c|}
\hline Population & 621 & 32 \\
\hline Sample & 112 & 16 \\
\hline Responses & & 16 \\
\hline Response Rates & & $100 \%$ \\
\hline
\end{tabular}

The 16 supervisors of the 112 workers surveyed in the sample, all of them completed the questionnaire and have been included in the analysis amounting to a response rate of $100 \%$.

\section{Tests and Interpretations}

Tests, Results and interpretations concerning the variables work experience and education and performance - are discussed in this section. There are only two questions proposed for this study and the task is to answer these based on the relevant tests.

\section{Question One}

Q1 - There will be significant variance among respondent's educational qualifications in terms of performance

One way ANOVA - Performance

\begin{tabular}{|c|c|c|c|c|c|}
\hline & Sum of Squares & Df $=\mathrm{n}-1$ & Mean Square & F & Sig. \\
\hline Between Groups & 433.930 & 5 & 86.786 & \multirow{2}{*}{1.399} & NS \\
\cline { 1 - 4 } Within Groups & 6575.489 & 106 & 62.033 & & \\
\hline Total & 7009.420 & 111 & & & \\
\hline
\end{tabular}

The result of the One Way ANOVA test given above is not significant. Hence we accept the statement -"there will be significant variance among respondent's educational qualifications in terms of performance". It implies that the employees with lesser education give a different performance then those who are relatively more educated (with a degree).

\section{Question Two}

Q2 - There will be no significant variance among respondents experience in terms of performance

One way ANOVA - Performance

\begin{tabular}{|c|c|c|c|c|c|}
\hline & Sum of Squares & Df $=\mathrm{n}-1$ & Mean Square & F & Sig. \\
\hline Between Groups & 96.698 & 4 & 24.174 & 0.374 & 0.827 \\
\hline Within Groups & 6912.722 & 107 & 64.605 & & \\
\hline Total & 7009.420 & 111 & & & \\
\hline
\end{tabular}

The above result of the One Way ANOVA test is at a significant level and it contradicts the statement that - "there will be no significant variance among respondents experience in terms of performance". Hence, we conclude that the performance of the employees is dependent on their work experience.

\section{Findings}

The findings of this research study are presented in this section. 1) The study shows that the performance exhibited by the employees varies due to their educational qualifications. The general trend is that with increasing educational qualifications the performance of the employees will decline. But, those who have only the higher secondary education perform better than those who have completed only the secondary education and this is an exception to the general rule in the middle. 2) The study indicates that the performance of the employees gradually increases with their experience and after an experience of 20 years the performance is again getting lower. This might be due to the fact that the employees lose interest in their work for having done their work for a long time and they feel sense of boredom in the work and there by perform lesser.

\section{Discussions}


This section is going to discuss, how the findings of this research work are relating to the other findings already established in the literature. It is good news that that are no contradicting findings out of this study and all the finding are in congruent with the facts already established.

a) The study shows that the performance exhibited by the workers varies due to their educational qualifications. The general trend is that with increasing educational qualifications the performance of the workers will decline. This finding of the study is in agreement with the findings of, Ben and Camilus (2012). It should be noted that this result is out of the study on the laborers and not the white color professionals.

b) The study indicates that the performance of the employees gradually increases with their experience and after an experience of 20 years the performance is again getting lower. With growing experience in a job, the employees learn almost all the knacks concerned with the job and nothing much remains to the learned. In the early stages of doing a job, there are many things to learn and individuals are curious to things and they will show interest on the job. But, when everything has been explored, repeating the same job again and again, gives the sense of boredom in the minds of the employees and this might affect on their performance negatively. Due to more involvement they lose interest in their jobs. This is just like the newly married couple showing more interest toward their spouse and later on the levels of interest will gradually decrease. Another factor is that after 20 years of experience the employees turn older and this in turn might affect their performance and this fact is in proved especially by the study of, Quinn, T. J. et al., (2011).

\section{Limitations of the Study}

Some of the limitations of this research study are: 1) only a sample is studied and not all the workers were studied in this research. 2) Only the select firm and not all other firms and industries were examined for this study. 3) The study is limited is geographically confined to a particular place. 4) In any research study the finance is the main financial constraint, the easily available questionnaires are used for this study. The performance questionnaire used in this study is the free versions available online. The other complex questionnaires are costly to purchase. So, the questionnaires used might have some inherent in-efficiencies. 5) Due to these reasons the results of this study might not be applicable general.

\section{Conclusions}

This is to conclude that the two variables chosen for this study - Education and WorkExperience - indeed have their respective influence on the performance of the workers. With change in any one of these two factors -Education and Work-Experience - will bring out a change in the performance of the worker. The study shows that with increase in the Work-Experience the workers tend to exhibit relatively better performance but, in the case of Education it is otherwise. When these factors increase greatly then the performance is found to decline even more - on the sample studied.

\section{References}

[1]. Andrew J. Dubrin, (2009), Leadership: Research Findings, Practice and Skills, 5 Ed, Houghton Mufiilin co., Boston, USA

[2]. Ahiazu, A. I. (1989). The "Theory A" system of work organization for the modern African workplace. International Studies of Management and Organization, 19(1), 6-27.

[3]. Ahmadi, A.A., Jalilian, H.J., Salamzadeh, Y., Saeidpour, B. and Daraei, M. (2012). Intellectual Capital and New Product Development Performance in Production Firms: A Case Study of Kermanshah Production Firms. Global Business and Management Research: An International Journal 4(1), 15-27.

[4]. Ahmadi, A.A., Ahmadi F., \& Shakeri S., (2011). The survey of relationship between Intellectual capital(IC) and Organizational performance (OP) within the National Iranian South Oil Company. Interdisciplinary Journal of Contemporary Research in Business 3(10), 135-143.

[5]. Ahangar, R.G. (2011). The relationship between intellectual capital and financial performance: An empirical investigation in an Iranian company. African Journal of Business Management 5(1), 88-95.

[6]. Al-Dujaili, M.A. (2012). Influence of Intellectual Capital in the Organizational Innovation. International Journal of Innovation, Management and Technology 3(2), 128-135

[7]. Allameh, S.M., Abbasi S., \& Shokrani S.A.R. (2010). The Mediating Role of Organizational Learning Capability between Intellectual Capital and Job Satisfaction. European Journal of Social Sciences 17(1), 125-136.

[8]. Amiri, A.N., Jandaghi, G., \& Ramezan, M. (2011). An Investigation to the Impact of Intellectual Capital on Organizational Innovation. European Journal of Scientific Research 64 (3), 472-477

[9]. Belal A. Kaifi, Bahaudin G. Mujtaba (2010), "Transformational Leadership of Afghans and Americans: A Study of Culture, Age and Gender", Journal of Service Science \& Management, doi:10.4236/jssm.2010.31019

[10]. Bless. C and Higson-Smith. C (2000), Fundamentals of Social Research Methods (3ed.), Lusaka, Juta Education (Pvt) Ltd.

[11]. Bontis, N. (2000). Assessing Knowledge Assets: A Review of the Models Used to Measure Intellectual Capital. Framework Paper 00-01, Queen's University at Kingston. Canada. Published in Queen's Management Research Centre for Knowledge-Based Enterprises.

[12]. Bontis, N. (2001). Managing Organizational Knowledge by Diagnosing Intellectual Capital: Framing and Advancing the State of the Field. McMaster University. Institute for Intellectual Capital Research Inc. (IICR). Hamilton, Ontario. Idea Group Publishing.

[13]. Cabrita, M., \& Bontis, N. (2008). Intellectual capital and business performance in the Portuguese banking industry. Int. J. Technology Management 43, Nos. 1-3, 212-237. 
[14]. Cagle,S.G. (1988). Fiedler's Contingency Theory of Leadership Effectiveness and Appointment of a Committee Chairperson. Dissertation Abstracts International, Volume: 50-07, Section: B, page: 2842

[15]. Garcya-Meca, E. \& Martynez, I. (2005). Assessing the Quality of Disclosure on Intangibles in the Spanish Capital Market. European Business Review 17(4), 305-313.

[16]. Ghorbani, M., Mofaredi, B. \& Bashiriya, S. (2012). Study of the relationship between intellectual capital management and organizational innovation in the banks. African Journal of Business Management 6(15), 5208-5217.

[17]. Gruian, C.M. (2011). The Influence of Intellectual Capital on Romanian Companies' Financial Performance. Annales Universitatis Apulensis Series Oeconomica 13(2), 260-272.

[18]. Hajiha, Z. \& Hasanloo, S. (2011). An Empirical Study of the Relationships among Human Capital Value and Profitability and Market Value: Comparison of Knowledge-Based Industries and Non-Knowledge- Based Industries. Asian Journal of Business and Management Sciences 1(3), 105-114.

[19]. Handzic, M. \& Ozturk, E. (2010). University Intellectual Capital: Measurement Model and Application. 2nd International Symposium on Sustainable Development, June 8-9 2010, Sarajevo, 740-747.

[20]. Hsiung, H.H. \& Wang, J.L. (2012). Value creation potential of intellectual capital in the digital content industry. Investment Management and Financial Innovations 9(2), 81-90.

[21]. Huang, C.J. \& Liu C.J. (2005). Exploration for the Relationship between Innovation, IT and Performance. Journal of Intellectual Capital, Vol. 6 No. 2, pp. 237-252.

[22]. Katozai, M. A. (2005). A Comprehensive Study of Education for Prospective Headmasters and Headmistresses, University publisher,Doger unique book Peshawar

[23]. Khalique, M.S., Jamal A.N., Md. Isa, A.H. \& Ageel, A. (2011). Relationship of Intellectual Capital with the Organizational Performance of Pharmaceutical Companies in Pakistan. Australian Journal of Basic and Applied Sciences 5(12), 1964-1969.

[24]. Kothari C. R (2001), Research Methodology (2ed), Wishwa Prakasan, New Delhi, India.

[25]. MacDougall, S.L. \& Hurst, D. (2005). Identifying Tangible Costs, Benefits and Risks of an Investment in Intellectual Capital: Contracting Contingent Knowledge Workers. Journal of Intellectual Capital 6(1), 53-71.

[26]. Maditinos, D., Chatzoudes, D., Tsairidis, C. \& Theriou, G. (2011). MIBES Transactions 5(1), 58-72.

[27]. Mujtaba. B. G. and Kaifi. B. A. (2008), "Afghan and American professionals' leadership orientation toward tasks and relationships: Are there tendencies toward convergence or divergence?” Fortune Journal of International Management, Vol. 5, No. 1, pp. 107125 .

[28]. Ngah, R. \& Ibrahim, A.R. (2009). The Relationship of Intellectual Capital, Innovation and Organizational Performance: a Preliminary Study in Malaysian SMEs. International Journal of Management Innovation Systems 1(1)

[29]. Ning, Y.T., Chen, C.H., Yen, L.S. \& Lun, T.C. (2011). Knowledge creation and intellectual capital on securities investment services. African Journal of Business Management 5(3), 924-933.

[30]. Nsubuga, Y. K. (2009). Analysis of Leadership Styles and School Performance of Secondary Schools in Uganda. Doctoral thesis. Port Elizabeth: Department of Education, Nelson Mandela Metropolitan University. Uganda.

[31]. Polanyi, Michael (1966), The Tacit Dimension, University of Chicago Press: Chicago, p.4

[32]. Rafiei, M., Feyzi, T., \& Azimi, H. (2011). Intellectual capital and its effect on economic performance: A Case Study in Iranian Automotive Industry. Journal of American Science 7(6), 497-507.

[33]. Rahman, S. (2012). The Role of Intellectual Capital in Determining Differences between Stock Market and Financial Performance. International Research Journal of Finance and Economics 89, 46-77.

[34]. Roos, G., Bainbridge, A. \& Jacobsen, K. (2001). Intellectual Capital Analysis as a Strategic Tool. International Capital Services (ICS) ltd. London. United Kingdom. Strategy and Leadership Journal 29(4), 21-26.

[35]. Seleim, A., Ashour, A., \& Bontis, N. (2007). Human capital and organizational performance: a study of Egyptian software companies. Management Decision 45(4), 789-801.

[36]. Sharabati, A., Jawad, S., \& Bontis, N. (2010). Intellectual Capital and Business Performance in the Pharmaceutical Sector of Jordan, Management Decision 48(1), 105-131.

[37]. Stewart, T.A. (2003). Intellectual Capital: the New Wealth of Organizations. London. Nicholas Brealey Publishing.

[38]. Taleghani, M., Shirsavar, H.A., \& Gashti, G.B. (2011). Determine of the Relationship between Dimensions of Intellectual Capital and Productivity of Education Organization of Guilan Province. Australian Journal of Basic and Applied Sciences 5(8), 1456-1460.

[39]. Trompenaars, F. (1993). Riding the waves of culture: Understanding diversity in global business. Chicago, IL: Irwin.

[40]. www.University of the Fraser Valley.com

[41]. Van Vugt. M (2006), "Evolutionary origins of leadership and followership," Personality\& Social Psychology Review, Vol. 10, No. 4, pp. 354-371.

[42]. Zambon, S. (2002). Accounting, Intangible and Intellectual Capital: an Overview of the Issues and some Considerations. Working Paper No. 4. University of Ferrara. 